\title{
A strategy for systemic delivery of the oncolytic herpes virus HSV1716: redirected tropism by antibody- binding sites incorporated on the virion surface as a glycoprotein $D$ fusion protein
}

\author{
J Conner, L Braidwood and SM Brown \\ Crusade Laboratories Ltd, Department of Neurology, Institute of Neurological Sciences, Southern General Hospital, Glasgow, Scotland, UK
}

\begin{abstract}
We report on the ability of single-chain variable fragment $(s c F v)$ incorporated into the viral envelope to alter the tropism of herpes simplex virus (HSV) 1716. Using recombinant viruses expressing fusion proteins comprising cellsurface antigen-specific scFvs $N$ terminus linked to amino acids 274-393 of $g D$, we demonstrated that the tropism of these HSV1716 variants was modified such that infection was mediated by the cognate antigen. Thus, an HSV1716 variant that expressed an anti-CD55 scFv targeting moiety linked to these $g D$ residues was able to infect non-permissive Chinese hamster ovary cells expressing CD55 and this infection was specifically blocked by an anti-CD55 monoclonal antibody. Similarly, the infection efficiency of an HSV1716 variant for semi-permissive human leukaemic,
\end{abstract}

CD38-positive cell lines was greatly improved by an antiCD38 scFv targeting moiety linked to gD residues 274-393, and this enhanced infectivity was abrogated specifically by an anti-CD38 monoclonal antibody. Finally, intravenous/ intraperitoneal injection of an HSV1716 variant displaying an anti-epidermal growth factor receptor (EGFR) scFv linked to residues 274-393 of $g D$ enhanced destruction of subcutaneous EGFR-positive tumours in nude mice compared to unmodified HSV1716. Therefore, targeting of HSV1716 oncolysis to specific cell types through the display of entry mediating $s c F v / g D$ fusion proteins represents an efficient route for systemic delivery.

Gene Therapy (2008) 15, 1579-1592; doi:10.1038/gt.2008.121; published online 14 August 2008

Keywords: oncolytic HSV1716; glycoprotein D; scFv-redirected tropism; systemic delivery

\section{Introduction}

Harnessing the cytopathic effects of virus infection is rapidly becoming established as an anti-cancer treatment and replication-competent mutants of the $\alpha$-herpesvirus, herpes simplex virus type 1 (HSV-1) are showing great potential as oncolytic therapeutic agents. ${ }^{1,2}$ The HSV-1 mutant 1716, lacking the ICP34.5 gene, has greatly reduced lethality in mice but replicates as efficiently as wild-type virus in actively dividing tissue culture cells. ${ }^{3,4}$ The ICP34.5 open reading frame (ORF) is a neurovirulence gene and its protein product has been proposed to condition post-mitotic cells for viral replication, probably by an interaction with proliferating cell nuclear antigen. ${ }^{5,6}$ ICP34.5 deletion mutants cannot replicate in terminally differentiated cells but will lytically infect dividing cells and this has proved to be an effective tumour destruction strategy. In recent clinical trials, injection of HSV1716 has been shown to be safe in treating patients with recurrent glioma, metastatic

Correspondence: Dr J Conner, Crusade Laboratories Ltd, Department of Neurology, Institute of Neurological Sciences, Southern General Hospital, 1345 Govan Road, Glasgow, Scotland G51 4TF, UK.

E-mail: jconner@crusadelabs.co.uk

Received 14 April 2008; revised 27 June 2008; accepted 30 June 2008; published online 14 August 2008 melanoma and squamous cell carcinoma of the head and neck ${ }^{7}$ and proof of principle of selective replication within tumours has been obtained. ${ }^{8-11}$

An essential strategy for the improved effectiveness of oncolytic viral therapies depends upon systemic delivery of targeted viruses that seek out and destroy all cancerous cells. ${ }^{2,12,13}$ Reprogramming viral tropisms has thus received much attention, an approach requiring redirection of the natural tropism from native receptors to a receptor of choice. Targeted infection by vaccinia virus, retrovirus and measles virus displaying singlechain antibody-binding sites $(\mathrm{scFv})$ incorporated into their structure by fusion with viral envelope proteins has been described. ${ }^{14-22}$ Bridging, bispecific targeting molecules comprising either an anti-adenovirus scFv or the Coxsackievirus-adenovirus receptor linked to a targeting $\mathrm{scFv}$, have been used for targeting oncolytic adenoviruses. ${ }^{23-29}$ Results from a number of studies with HSV1 have shown that it is possible to alter the tropism by incorporating ligands such as erythropoietin, interleukin (IL) 13, human hepatitis B virus preS1 peptide, the N-terminal fragment of urokinase-type plasminogen activator or 6-His into the viral envelope as glycoprotein fusion proteins. ${ }^{30-35}$ Targeting has also been achieved using a soluble adapter molecule comprising an antiepidermal growth factor receptor (EGFR) scFv linked to the HSV-1 gD-binding domain of nectin-1 and more 
recently, a scFv against HER2/neu incorporated into the $\mathrm{N}$ terminus of $\mathrm{gD}$ has been shown to redirect the tropism of HSV-1 to this mammary tumour receptor. ${ }^{36,37}$

Initiation of infection by HSV-1 requires cells to display the appropriate receptors to permit viral access, a process requiring the complex interplay of a number of cellular and viral membrane components. ${ }^{38,39}$ Four virus membrane glycoproteins, $\mathrm{gB}, \mathrm{gD}$ and the heterodimer comprising $\mathrm{gH}$ and $\mathrm{gL}(\mathrm{gH} / \mathrm{gL}$ ) have been shown to be necessary and sufficient for HSV-1 entry into cells. Initial contact is between $\mathrm{gB}$ and cellular heparan sulphate, $\mathrm{gD}$ then interacts specifically with the cellular receptors for HSV-1 entry that include herpesvirus entry mediator (HVEM), nectins-1 and -2 and 3-O-sulphated heparan sulphate. Membrane fusion requires the concerted activities of $\mathrm{gB}$ and $\mathrm{gH} / \mathrm{gL}$ so that the nucleocapsid gains access to the cell and infection is initiated. Nectin-1 is probably the principal entry receptor for infection of central and peripheral nerve cells whereas HVEM expression is more restricted and limited to cells of lymphoid origin. ${ }^{40-44}$ Wide bioavailability of HSV-1 entry mediators will create problems for the efficient systemic administration of oncolytic HSV1716 and we have investigated therefore the possibility of redesigning the viral tropism by scFv embedded in the viral envelope by fusion with the C-terminal tail of $\mathrm{gD}$. Our results demonstrated that membrane-displayed scFv linked to gD specifically influenced the tropism of HSV1716 thus allowing development of effective tumour-targeted HSV1716 for systemic delivery.

\section{Results}

Preliminary data obtained using viruses that displayed scFvs linked to 15 sequentially deleted N-terminal truncations of HSV-1 gD ( $\mathrm{scFv} / \mathrm{gD}$ ) identified a minimal fragment of the protein, comprising residues 274-393, which functioned optimally to redirect the tropism of the virus. Analysis of the effects of $\mathrm{scFv} / \mathrm{gD}$ glycoprotein fusion proteins on tropism used infection of nonpermissive Chinese hamster ovary (CHO) cells by viruses propagated on stable Vero cell lines expressing the $\mathrm{scFv} / \mathrm{gD}$ glycoprotein fusion proteins. As gangliosides are ubiquitous components of cell membranes and GD3 was present on CHO cells as determined using the anti-GD3 monoclonal antibody (mAb) R24 (data not shown), an scFv derived from the R24 mAb was used in this initial study. The DNA encoding each fusion protein construct was assembled in the pEL4-mammalian-expression vector, containing the $\mathrm{R} 24 \mathrm{scFv}$ such that the expressed protein consisted of a secretory leader sequence, an N-terminal scFv domain for binding to a targeting ligand linked to viral glycoprotein $\mathrm{D}$ domains for virus incorporation and a myc-tag appended to the $\mathrm{C}$ terminus of the glycoprotein $\mathrm{D}$ domains for detection by immunofluorescence and western blotting. Linear representations of HSV-1 $\mathrm{gD}$ and a typical $\mathrm{scFv} / \mathrm{gD}$ fusion protein are shown in Figure $1 \mathrm{a}(\mathrm{i})$ and (ii), respectively. All $15 \mathrm{gD}$ deletions were linked to the $\mathrm{C}$ terminus of the R24 scFv and stable Vero cell lines expressing the scFv/ $\mathrm{gD}$ fusion proteins were created by antibiotic selection. Vero cell localization and expression of the myc-tagged fusion proteins was demonstrated by immunofluorescence and western blotting and incorporation into virus was assessed by western blotting of purified virion preparations obtained after HSV1716gfp infection of the cell lines. The results are summarized in Table 1 . In total, 2 of the $15 \mathrm{R} 24 \mathrm{scFv} / \mathrm{gD}$ fusion protein constructs, with the $\mathrm{R} 24 \mathrm{scF}$ linked to residue 58 of $\mathrm{gD}(\mathrm{R} 24 / 58 \mathrm{gD})$ and the $\mathrm{R} 24 \mathrm{scFv}$ linked to residue 105 of $\mathrm{gD}$ (R24/105gD), were not expressed. Of the expressed fusion proteins, only the R24scFv linked to residue 164 of gD (R24/ $164 \mathrm{gD}$ ) and the R24scFv linked to residue 231 of gD (R24/ 231gD) were not incorporated into virus. All expressed $\mathrm{R} 24 \mathrm{scFv} / \mathrm{gD}$ fusion proteins, including R24/164gD and $\mathrm{R} 24 / 231 \mathrm{gD}$, which were not incorporated into virus, demonstrated a distinctive perinuclear accumulation with some immunofluorescent patches present at the plasma membrane (data not shown). No fluorescence was observed in cells that failed to express R24/58gD and R24/105gD. The cellular localization of the expressed fusion proteins is consistent with an accumulation in the nuclear membrane/endoplasmic reticulum and further trafficking of the fusion proteins probably through the Golgi apparatus to the outer membrane of the cell.

$\mathrm{CHO}$ cells, normally resistant to HSV1716 infection when the virus is propagated on Vero cells, were infected with 1 PFU per cell HSV1716gfp derived from infection of $\mathrm{R} 24 / \mathrm{gD}$ fusion protein-expressing cell lines and the percentages of infected cell determined by fluorescence microscopy (Table 1). HSV1716gfp propagated on Vero cells (HSV1716V) failed to infect CHO cells and this contrasts with HSV1716gfp propagated on Baby-hamster kidney (BHK) cells (HSV1716B) that infects approximately $30 \%$ of $\mathrm{CHO}$ cells. A number of HSV1716gfp viruses derived from propagated on Vero cell lines expressing $\mathrm{R} 24 / \mathrm{gD}$ fusion proteins were able to infect $\mathrm{CHO}$ cells at levels similar to or greater than those obtained with HSV1716B. Thus, the R24scFv linked to gD residues 37 (R24/37gD), 78 (R24/78gD), $92(\mathrm{R} 24 / 92 \mathrm{gD})$, 128 (R24/128gD), 260 (R24/260gD) and 274 (R24/274gD) infected 27, 11, 20, 18, 60 and 55\%, respectively, of CHO cells compared to only occasionally infected $\mathrm{CHO}$ cells for the other R24/gD fusion proteins.

On the basis of these observations, we produced a series of targeted recombinant viruses with expression cassettes for anti-CD20 (HSV1716CD20), anti-CD38 (HSV1716CD38), anti-CD55 (HSV1716DAF) or antiEGFR (HSV1716EGFR) scFvs fused to residues 274-393 of $\mathrm{gD}$ inserted in the RL1 loci. Expression of the $\mathrm{scFv} / \mathrm{gD}$ fusion proteins was controlled by the constitutively active CMV-IE promoter and the fusion proteins comprised a secretory leader sequence, $\mathrm{N}$-terminal $\mathrm{scFv}$ for binding to a targeting ligand linked to C-terminal viral glycoprotein D residues 274-393 for virus incorporation with a myc-tag appended at the $\mathrm{C}$ terminus for detection by immunofluorescence/western blotting (see Figure 1a(ii)). These targeted HSV1716 variants were generated using a novel HSV1716GateRed site-specific recombination system that also inserted a PGK-gfpexpression cassette in tandem with and in the same orientation as the $\mathrm{scFv} / \mathrm{gD}$-expression cassette. Linear representations of the $\mathrm{scFv} / 274 \mathrm{gD}$ fusion protein-expression cassette, the $\mathrm{scFv} / 274 \mathrm{gD}$ fusion protein-expression cassette inserted in the Gateway entry vector pENTR1Agfp, the destination vector HSV1716GateRed at the RL1 loci and the viral product of recombination between the entry and destination vectors are shown in 


\begin{tabular}{|c||c|c|}
\hline$T$ & $\begin{array}{c}\text { Pro- } \\
\text { fusion }\end{array}$ & receptor binding \\
\hline
\end{tabular}
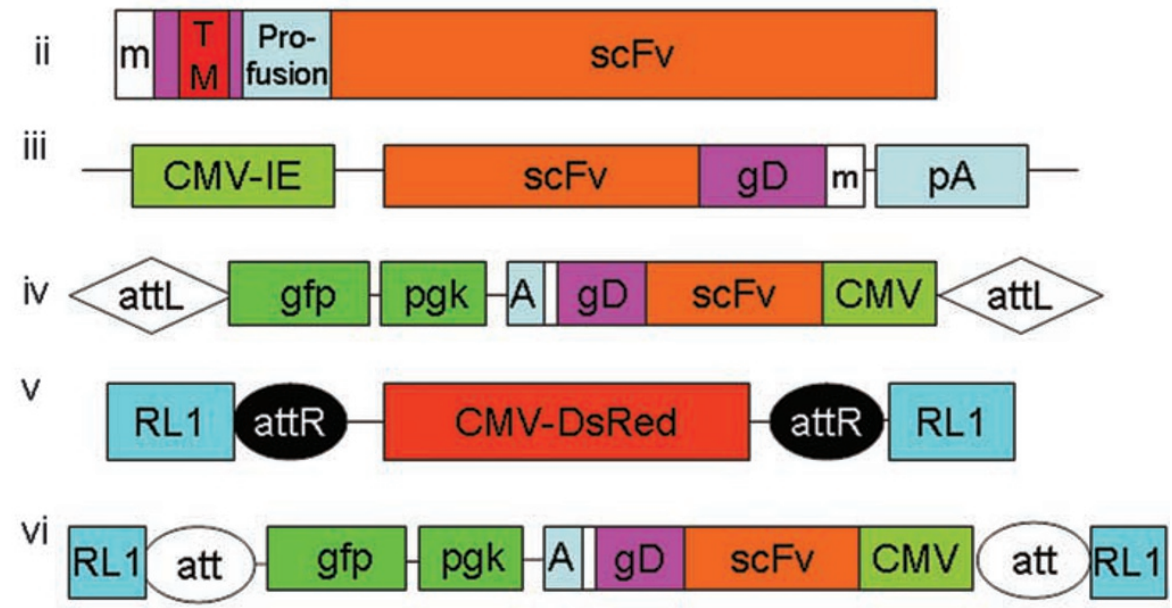

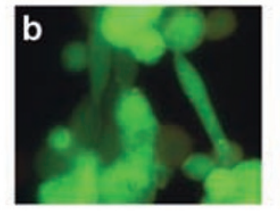

1716CD20-gfp

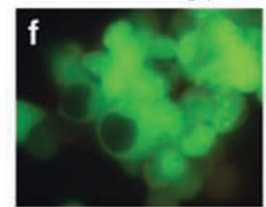

1716CD38-gfp

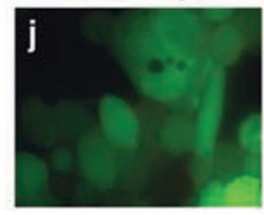

1716CD20neg-gfp

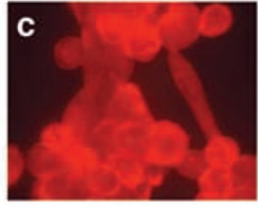

1716CD20-myc

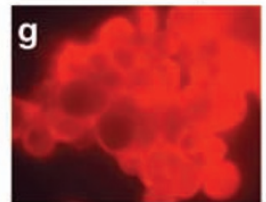

1716CD38-myc

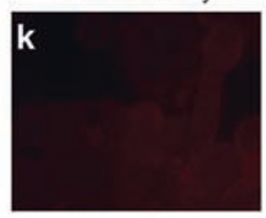

1716CD20neg-myc

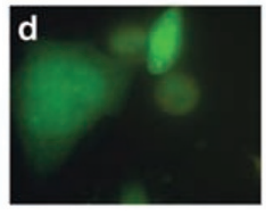

1716DAF-gfp

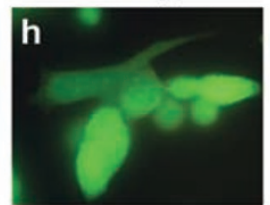

1716EGFR-gfp

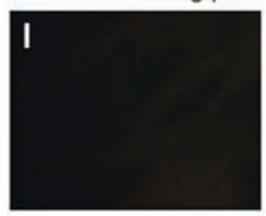

BHK-gfp

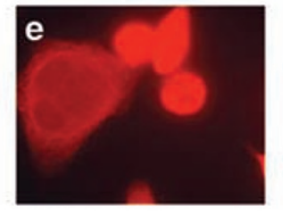

1716DAF-myc

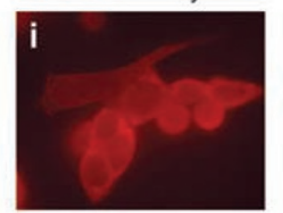

1716EGFR-myc

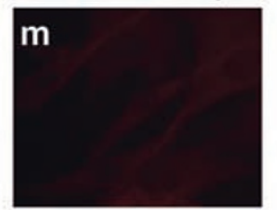

BHK-myc

Figure 1 (a) Linear representations (not to scale) of (i) HSV-1 gD structure showing the regions of the protein involved in receptor binding, profusion activity and insertion in the viral membrane (TM), (ii) the single-chain variable fragment (scFv)/274gD fusion protein structure relative to $\mathrm{gD}$ showing the location of the $\mathrm{scFv}$-binding domain and regions involved in profusion activity, membrane insertion and the myc tag (m), (iii) the scFv/274gD fusion protein-expression cassette used for recombinant virus production, CMV-IE: CMV immediate early promoter and pA: bovine growth hormone polyadenylation signal, (iv) the multiple cloning site located between the attL site-specific recombination sequences of the vector pENTR1Agfp showing pgk-gfp and CMV-scFv/274gD-BGHpA-expression cassettes, (v) the HSV1716GateRed genome within the RL1 loci showing the attR site specific recombination sequences flanking the CMV-DsRed-expression cassette within the deleted region of the ICP34.5 gene and (vi) the viral product from site-specific recombination between (iv) and (v) with pgk-gfp and CMV-scFv/274gD-BGHpA-expression cassettes now inserted in the RL1 loci. (b-m) Immunofluorescence/fluorescence microscopy of Baby-hamster kidney (BHK) cells infected with HSV1716CD20 (b, c), HSV1716DAF (d, e), HSV1716CD38 (f, g), HSV1716EGFR $(\mathbf{h}, \mathbf{i})$ or HSV1716CD20neg $(\mathbf{j}, \mathbf{k})$. Mock-infected BHK cells are shown in $\mathbf{l}$ and $\mathbf{~} \mathbf{m}$. Staining with the anti-myc monoclonal antibody is shown in $\mathbf{c}, \mathbf{e}, \mathbf{g}, \mathbf{i}, \mathbf{k}, \mathbf{m}$ and gfp is shown in $\mathbf{b}, \mathbf{d}, \mathbf{f}, \mathbf{h}, \mathbf{j}, \mathbf{l}$.

Figure 1a(iii)-(vi), respectively. Expression of the $\mathrm{scFv} /$ $274 \mathrm{gD}$ proteins in infected cells was demonstrated by immunofluorescence using the anti-myc tag mAb (Figures $1 b-m$ ) with cytoplasmic/perinuclear distributions observed in BHK cells infected with HSV1716CD20 (Figure 1c), HSV1716DAF (Figure 1e), HSV1716CD38 (Figure 1g) and HSV1716EGFR (Figure 1i). Expression of gfp was also observed in cells infected with these viruses (Figures $1 b, d, f$ and $h$ ). Additionally, an HSV1716 variant in which the expression cassette for the anti-CD20
$\mathrm{scFv}$ linked to residue 274 of $\mathrm{gD}$ was in the opposite orientation relative to PGK-gfp was created (HSV1716CD20neg) and this variant failed to express a protein product as only gfp expression was observed (Figures 1j and k). Mock-infected BHK cells are shown in Figures 11 and $\mathrm{m}$. Expression of the $\mathrm{scFv} / 274 \mathrm{gD}$ fusion proteins following infection of $\mathrm{BHK}$ cells was also confirmed by western blotting of whole-cell extracts using an anti-myc tag mAb (data not shown). A $45 \mathrm{kDa}$ protein was detected with HSV1716CD20, HSV1716DAF, 
Table 1 Expression and $\mathrm{CHO}$ cell infection data from R24 scFv linked to $15 \mathrm{~N}$-terminal deletions of HSV-1 gD

\begin{tabular}{|c|c|c|c|c|c|}
\hline Construct & Approx $M W t(k D a)^{\mathrm{a}}$ & Vero cell expression ${ }^{\mathrm{b}}$ & Virus incorp ${ }^{\mathrm{b}}$ & Localization in Vero cells & $\mathrm{CHO}$ cell infectivity ${ }^{\mathrm{C}}$ \\
\hline $\mathrm{R} 24 / 37 \mathrm{gD}$ & 70 & ++ & ++ & Perinuclear & $27 \%$ \\
\hline R24/58gD & 67 & ND & ND & $\mathrm{ND}$ & $<1$ \\
\hline R24/79gD & 65 & ++ & ++ & Perinuclear & $11 \%$ \\
\hline R24/92gD & 64 & ++ & ++ & Perinuclear & $20 \%$ \\
\hline $\mathrm{R} 24 / 105 \mathrm{gD}$ & 61 & ND & ND & ND & $<1$ \\
\hline R24/128gD & 60 & ++ & ++ & Perinuclear & $18 \%$ \\
\hline R24/139gD & 59 & ++ & + & Perinuclear & $<1$ \\
\hline R24/164gD & 56 & ++ & ND & Perinuclear & $<1$ \\
\hline R24/179gD & 55 & ++ & + & Perinuclear & 3 \\
\hline R24/191gD & 54 & ++ & + & Perinuclear & $<1$ \\
\hline R24/207gD & 52 & ++ & + & Perinuclear & $<1$ \\
\hline R24/231gD & 49 & ++ & ND & Perinuclear & $<1$ \\
\hline R24/239gD & 48 & ++ & + & Perinuclear & $<1$ \\
\hline $\mathrm{R} 24 / 260 \mathrm{gD}$ & 46 & ++ & ++ & Perinuclear & $60 \%$ \\
\hline $\mathrm{R} 24 / 274 \mathrm{gD}$ & 44 & ++ & ++ & Perinuclear & $55 \%$ \\
\hline
\end{tabular}

Abbreviations: Approx, approximately; $\mathrm{CHO}, \mathrm{Chinese}$ hamster ovary; incorp, incorporation; ND, not detected.

${ }^{a}$ Fusion protein $\mathrm{MWt}=\mathrm{scFv}(30 \mathrm{kDa})+\mathrm{gD}$ amino acids.

${ }^{b}$ Band intensity from western blots; high, +++ ; intermediate, ++ ; low,+ .

cPercentage of CHO cells infected per field of view, two fields of view counted per virus.

HSV1716CD38 and HSV1716EGFR that was absent from mock infected or from BHK cells infected with HSV1716 or HSV1716CD20neg. SDS-polyacrylamide gel electrophoresis (PAGE)/western blotting using the anti-myc $\mathrm{mAb}$ on $1 \times 10^{6}$ PFU HSV1716CD20, HSV1716DAF, HSV1716CD38 and HSV1716EGFR confirmed that the $\mathrm{scFv} / 274 \mathrm{gD}$ fusion protein was incorporated into virus (data not shown). Virus stocks of HSV1716CD20, HSV1716DAF, HSV1716CD38, HSV1716EGFR and HSV1716CD20neg were prepared by propagation in Vero cells in T175 flasks and the yields of each virus ( $4 \times 10^{9}$ PFU per flask) were within the range of yields for HSV1716 propagation on Vero cells suggesting that the expression and incorporation of the targeting moiety did not influence replication efficiency.

Using fluorescence microscopy, the abilities of these viruses to infect $\mathrm{CHO}, \mathrm{CHO} /$ decay-accelerating factor (DAF), SupT, THP-1 and TolB cells were assessed either in the presence or absence of $\mathrm{mAbCD} 20, \mathrm{mAbCD} 38$, mAbDAF or mAbEGFR, the mAbs from which the antiCD20, anti-CD38, anti-DAF or anti-EGFR scFvs were cloned. THP-1 and SupT are monocyte and T-cell lines, respectively, that express CD38 but not CD20 and TolB is a B-cell line that expresses both CD38 and CD20, although levels of CD20 expression in TolB cells were apparently low as only weak fluorescence was observed with TolB/mAbCD20. We also created a CHO cell line (CHO/DAF) that constitutively expressed human DAF as demonstrated by immunofluorescence with mAbDAF (Figure 2a) and a recombinant minibody version of mAbDAF (rmAbDAF; Figure 2b) with intense membrane staining of DAF in the $\mathrm{CHO} / \mathrm{DAF}$ cells but not with normal $\mathrm{CHO}$ cells (Figure 2c).

Only occasional $\mathrm{CHO}$ cells were infected by HSV1716CD20, HSV1716CD38 or HSV1716DAF (Figures $2 \mathrm{~d}-\mathrm{f}$, respectively) compared to approximately $20 \%$ of $\mathrm{CHO}$ cells infected with HSV1716gfp propagated in BHK cells (HSV1716B; Figure 2g). HSV1716CD20 (Figure 2h) and HSV1716CD38 (Figure 2i) were also unable to infect $\mathrm{CHO} / \mathrm{DAF}$ cells although, as with CHO cells, HSV1716B infected approximately $30 \%$ of $\mathrm{CHO} / \mathrm{DAF}$ cells (Figure 2k). Significantly, HSV1716DAF was able to infect approximately $60 \%$ of $\mathrm{CHO} / \mathrm{DAF}$ cells (Figure $2 \mathrm{j}$ ) and, by pre-incubating the $\mathrm{CHO} / \mathrm{DAF}$ cells in mAbDAF (Figure $2 \mathrm{~m}$ ) or the rmAbDAF (Figure $2 \mathrm{n}$ ), this level of infectivity was reduced to approximately 5\%. Preincubation of $\mathrm{CHO} / \mathrm{DAF}$ cells in mAbCD20 (Figure 21) had no effect on the infectivity of the HSV1716DAF with approximately $70 \%$ of cells infected and pre-incubation of $\mathrm{CHO} / \mathrm{DAF}$ in mAbDAF did not inhibit HSV1716B infectivity (Figure 2o).

The fluorescence microscopy data was confirmed by western blotting using an anti-HSV-1 R1 antiserum to probe whole-cell extracts from $\mathrm{CHO} / \mathrm{DAF}$ cells. R1 expression was only detected in $\mathrm{CHO} / \mathrm{DAF}$ cells infected with HSV1716DAF with no expression detected in $\mathrm{CHO} / \mathrm{DAF}$ cells infected with HSV1716CD20 or HSV1716CD38 (data not shown). Thus, viruses that displayed a targeting moiety against DAF were better able to infect $\mathrm{CHO}$ cells with membrane-exposed DAF than viruses that displayed targeting moieties directed against CD20 or CD38, not present on $\mathrm{CHO}$ cells.

SupT, THP-1 and TolB cells were semi-permissive for HSV1716 infection with between 10 and $30 \%$ of SupT, THP-1 or TolB cells infected by HSV1716gfp in three separate experiments and this level of infection was unaffected by pre-incubation of the cells in mAbCD20, $\mathrm{mAbCD} 38$ or control medium (Figures $3 \mathrm{a}-\mathrm{c}$, respectively). HSV1716CD20 or HSV1716CD20neg were also only able to infect similar numbers of SupT (Figure 3a), THP-1 (Figure 3b) or TolB (Figure 3c) cells and, again, these levels of infection were unaffected by pre-incubation of the cells in mAbCD20, mAbCD38 or control medium. In contrast, HSV1716CD38 was able to infect 60-90\% of the CD38-positive SupT (Figure 3a), THP-1 (Figure 3b) or TolB (Figure 3c) cells and, significantly, these higher levels of infection were reduced to $5-30 \%$ by pre-incubating the cells in mAbCD38 but were unaffected by pre-incubating the cells in $\mathrm{mAbCD} 20$ or control medium. Analysis of variance (ANOVA) generated highly significant $P$-values $(0.004<P<0.012)$ only for HSV1716CD38 infection of SupT, THP-1 and TolB cells in the presence of $\mathrm{mAbCD} 20$ or control medium but not in the presence of $\mathrm{mAbCD} 38$ indicating that the CD38- 


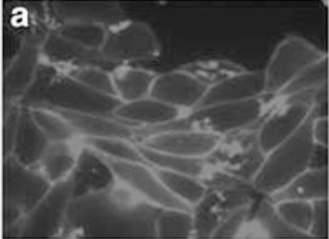

CHO/DAF-mAbDAF

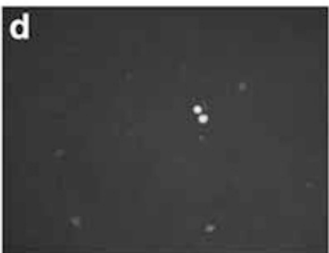

$1716 \mathrm{CD} 20-\mathrm{CHO}$

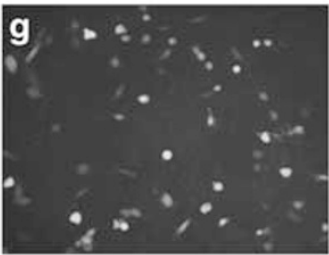

1716B-CHO

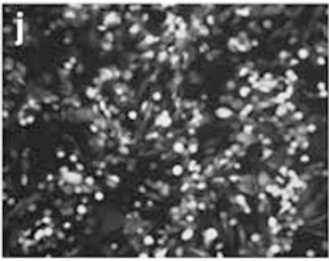

1716DAF-CHODAF

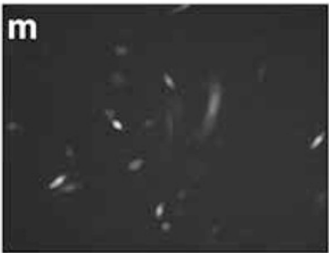

1716DAF-CHODAF-mAbDAF 1716DAF-CHODAF-rmAbDAF

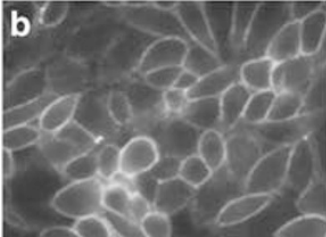

CHOIDAF-rmAbDAF

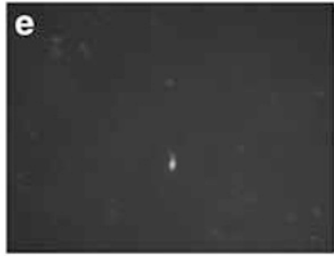

$1716 \mathrm{CD} 38-\mathrm{CHO}$

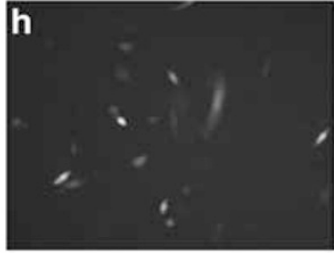

1716CD20-CHODAF

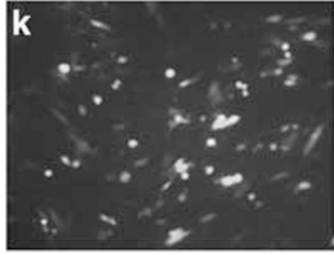

1716B-CHODAF

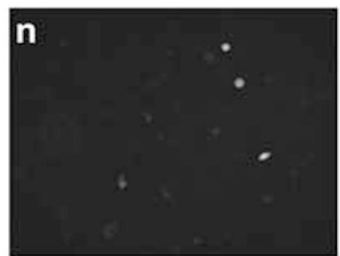

1716DAF-CHODAF-mAbCD20

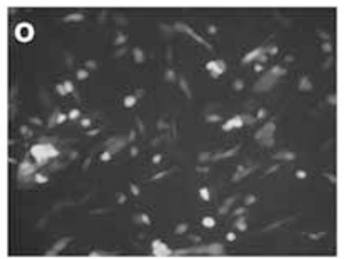

1716B-CHODAF-mAbDAF

Figure 2 Immunofluorescence with monoclonal antibody decay-accelerating factor (mAbDAF; $\mathbf{a}, \mathbf{c}$ ) and a recombinant minibody version of mAbDAF (b) demonstrating expression of DAF by Chinese hamster ovary (CHO)/DAF (a, b) but not by normal CHO (c) cells. Fluorescence microscopy demonstrating levels of $\mathrm{CHO}(\mathbf{d}-\mathbf{g})$ or $\mathrm{CHO} / \mathrm{DAF}(\mathbf{h}-\mathbf{o})$ cell infection by HSV1716B $(\mathbf{g}, \mathbf{k}$, o) or by Vero cell propagated HSV1716CD20 (d, h), HSV1716CD38 (e, i) or HSV1716DAF $(\mathbf{f}, \mathbf{j}, \mathbf{1}-\mathbf{n})$. CHO/DAF cells were pre-incubated in mAbDAF (m, o), recombinant mAbDAF (n) or mAbCD20 (1).

binding sites displayed on the HSV1716CD38 envelope significantly influenced tropism. Additionally, the similarities in the levels of HSV1716 or HSV1716CD20 infection of SupT, THP-1 or TolB cells indicates that the presence of the targeting moiety in the viral envelope does not influence the normal route of infection.

Unfortunately, we were unable to identify a human tumour cell line that was EGFR-positive and resistant to HSV1716 infection for in vitro analysis of HSV1716EGFR. For example, the human epidermoid carcinoma cell line A431 expresses EGFR as demonstrated by mAbEGFR binding to the cell surface (Figures $4 \mathrm{~b}$ and $\mathrm{d}$ ) and showed similar levels of susceptibility to HSV1716gfp or HSV1716EGFR infection, as assessed by gfp expression (Figures $4 \mathrm{a}$ and c). Further, duplicate infections of A431 cells in $60 \mathrm{~mm}$ dishes with 20 PFU HSV1716 or HSV1716EGFR produced similar yields of $1.1 \times 10^{6}$ and $1.25 \times 10^{6}$ PFU or $1.0 \times 10^{6}$ and $1.45 \times 10^{6}$ PFU, respectively. Thus, in vitro, there was no apparent difference in replication of either HSV1716 or HSV1716EGFR on A431 cells again indicating that the expression and incorporation of the targeting moiety did not impair virus replication.

Nude mice bearing subcutaneous A431 tumours were systemically injected in the tail vein with phosphatebuffered saline (PBS) or $1 \times 10^{6}$ PFU HSV1716 or HSV1716EGFR on days 1 and 3, tumours were measured daily and mice were killed once the tumours had reached $15 \mathrm{~mm}$ diameter. Mice that received the control PBS injection had more rapidly growing tumours than mice 

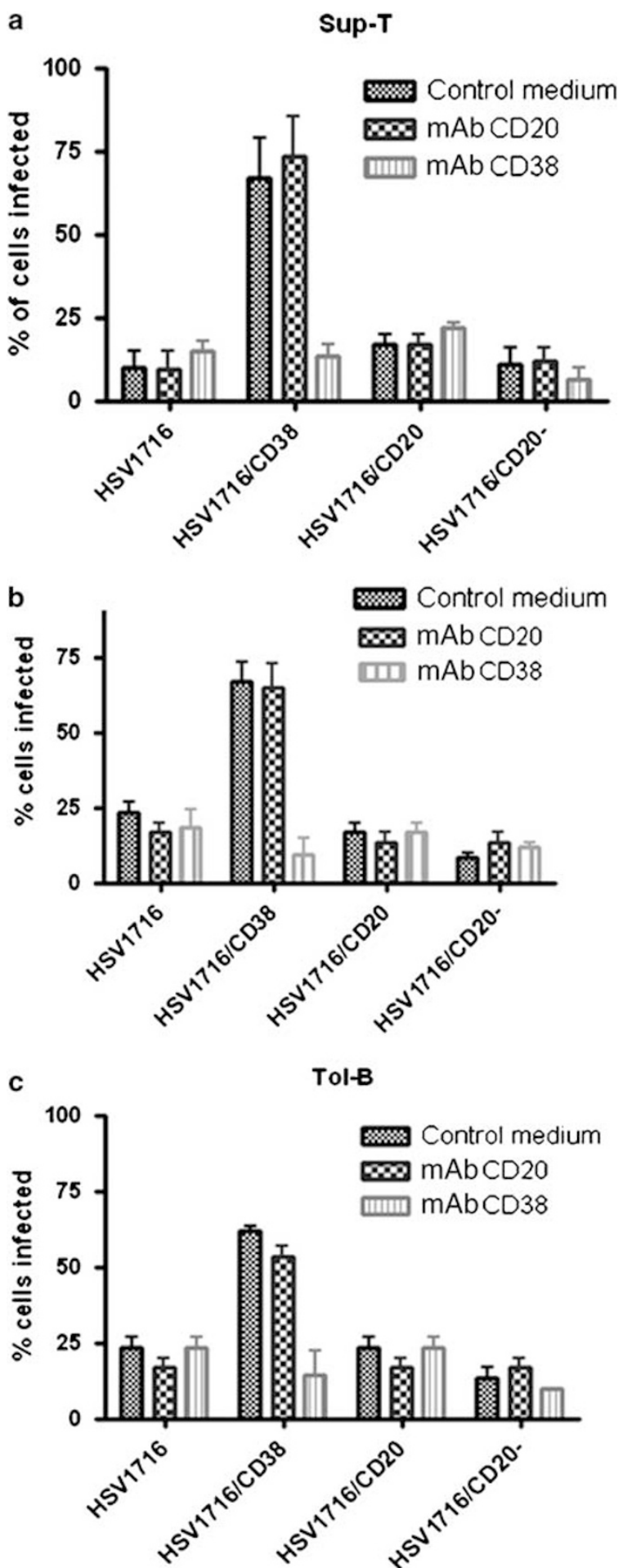

Figure 3 Graphs showing percentages of SupT (a), THP-1 (b) or TolB (c) cells infected by HSV1716gfp, HSV1716CD20, HSV1716CD38 or HSV1716CD20neg. Cells were pre-incubated in control medium, mAbCD20 or mAbCD38. Data are from a single representative field of view from three different experiments.

that received HSV1716 and were killed sooner. Mice that received HSV1716EGFR had more slowly growing tumours and survived longer than those that were injected with HSV1716 (Figure 5a). However, in this initial experiment, the tumours from several mice receiving intravenously injected HSV1716EGFR were actually much smaller than measurements suggested as they formed a capsule-like structure, the majority of which was cellular debris, presumably a consequence of extensive viral replication and, consistent with this, large amounts of virus were extracted from tumours of mice injected with HSV1716EGFR compared to HSV1716injected mice. Thus, $3.1 \times 10^{5}, 5.2 \times 10^{6}$ or $8.7 \times 10^{6} \mathrm{PFU}$ were extracted from tumours of mice killed on days 16, 23 or 24, respectively, after HSV1716EGFR injection compared to 0,0 or $4.1 \times 10^{3}$ PFU extracted from HSV1716-injected mouse tumours on days 16, 17 or 17, respectively. Immunohistochemical analysis of excised tumours clearly demonstrated more extensive virus antigen expression following injection of HSV1716EGFR (Figures 4d and e) compared to the smaller, more localized focus of unmodified HSV1716 antigen expression (Figure 4f) with no viral antigen detected in the PBSinjected control tumours (Figure $4 \mathrm{~g}$ ). The failure to detect any virus in two out of three tumour extracts from HSV1716-injected mice is consistent with the small localized foci of virus replication observed immunohistochemically in these tumours or, alternatively, after intravenous injection, little or no unmodified HSV1716 lodged in these tumours. In a subsequent experiment using intravenous injection, HSV1716EGFR was again more effective at reducing tumour burdens and prolonging survival compared to HSV1716 (Figure 5b) with mean survival times for no virus, HSV1716 or HSV1716EGFR of 10, 19 or 25.5 days, respectively. No virus was extracted from the skin, heart, liver, gut, lung, brain, bone, spleen or kidney of several mice injected with HSV1716EGFR and this lack of virus in these organs was confirmed using an HSV-1-specific PCR with DNA extracted from these tissues as template.

Further evidence of HSV1716EGFR tumour targeting was provided by intraperitoneal injection of nude mice bearing subcutaneous A431 tumours. On days 1, 3, 5, 6 and 9 the mice were injected with PBS or $2 \times 10^{6}$ PFU HSV1716 or HSV1716EGFR. When injected by this route, HSV1716 was ineffective as the median survival time for both PBS- and HSV1716-injected mice was 18.5 days. Tumour growth was significantly reduced in mice receiving HSV1716EGFR (Figure 5c, Table 2), resulting in a prolonged median survival of 28 days for the HSV1716EGFR-injected mice. Thus, by intraperitoneal injection, presumably, insufficient HSV1716 must reach the subcutaneous tumours to have any effect on tumour growth whereas targeting the virus to EGFR on the tumour cell surface promoted improved tumour uptake and prolonged survival.

\section{Discussion}

Recent phase 1 clinical trials have demonstrated an excellent safety profile following direct intratumoural injection of oncolytic HSV1716 and the efficacy of this virus is being investigated currently in a phases II/III trial for the treatment of recurrent glioma. It is clear however that the therapeutic usefulness of HSV1716 will be greatly facilitated if the virus can be administered by the circulation. In addition, the platform of tumour indications viz haematological tumours and metastatic disease, susceptible to oncolytic viral therapy could be 

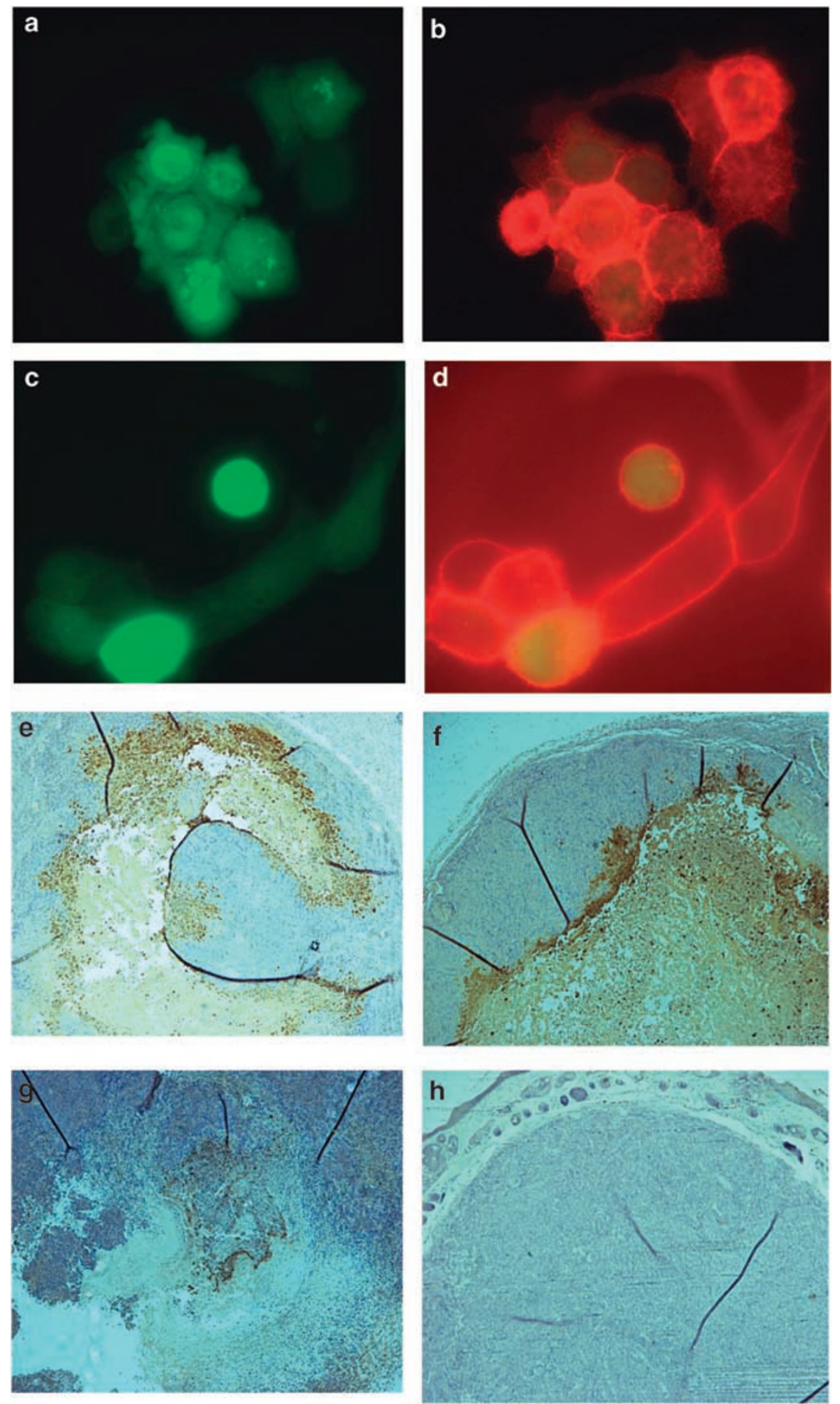

Figure 4 (a-d) Immunofluorescence/fluorescence microscopy of A431 cells infected with HSV1716EGFR (a, b) or HSV1716 (c, d). Gfp fluorescence is shown alone in (a, c), and is shown combined with mAbEGFR immunofluorescence in (b, d). (e-h) Immunohistochemistry using an anti-HSV-1 antiserum on tumours from nude mice bearing subcutaneous A431 tumours after intravenous injection of HSV1716EGFR (e, f), HSV1716 (g) or no virus (h). Tumours were excised on day 23 for HSV1716EGFR, day 18 for HSV1716 and day 9 for no virus.

greatly expanded. Incorporation of tumour-targeting moieties into the virus structure is a prerequisite for such strategies.

A number of reports have shown that various ligands linked to $\mathrm{gC}$ have been able to influence the tropism of HSV-1. Laquerre et al., ${ }^{30}$ using a virus deleted for the heparan sulphate-binding region of $\mathrm{gB}$, substituted $\mathrm{gC}$ with modified versions in which erythropoietin replaced residues $1-161,83-161$ or $1-375$ of the protein. The fusion protein with erythropoietin inserted between residues 83 and 161 was able to mediate uptake but not infection of a non-permissive erythropoietin receptor-bearing cell line. Viruses that lacked the heparan sulphate-binding region of $\mathrm{gB}$ and with either the cytokine IL13 both replacing residues 1-148 of $\mathrm{gC}$ and inserted between residues 24 and 25 of $\mathrm{gD}$ or with residues 20 to 155 
of the urokinase plasminogen activator inserted between $\mathrm{gD}$ residues 24 and 25 were able to infect specifically cells expressing the cognate receptor. ${ }^{31,32,34}$ Infection of a hepatoblastoma cell line by viruses in which the human hepatitis B virus hepatocyte-binding preS1 protein or its minimally active peptide respectively replaced gC amino acids (aa) 149-213 or 149-442 was blocked by anti-preS1
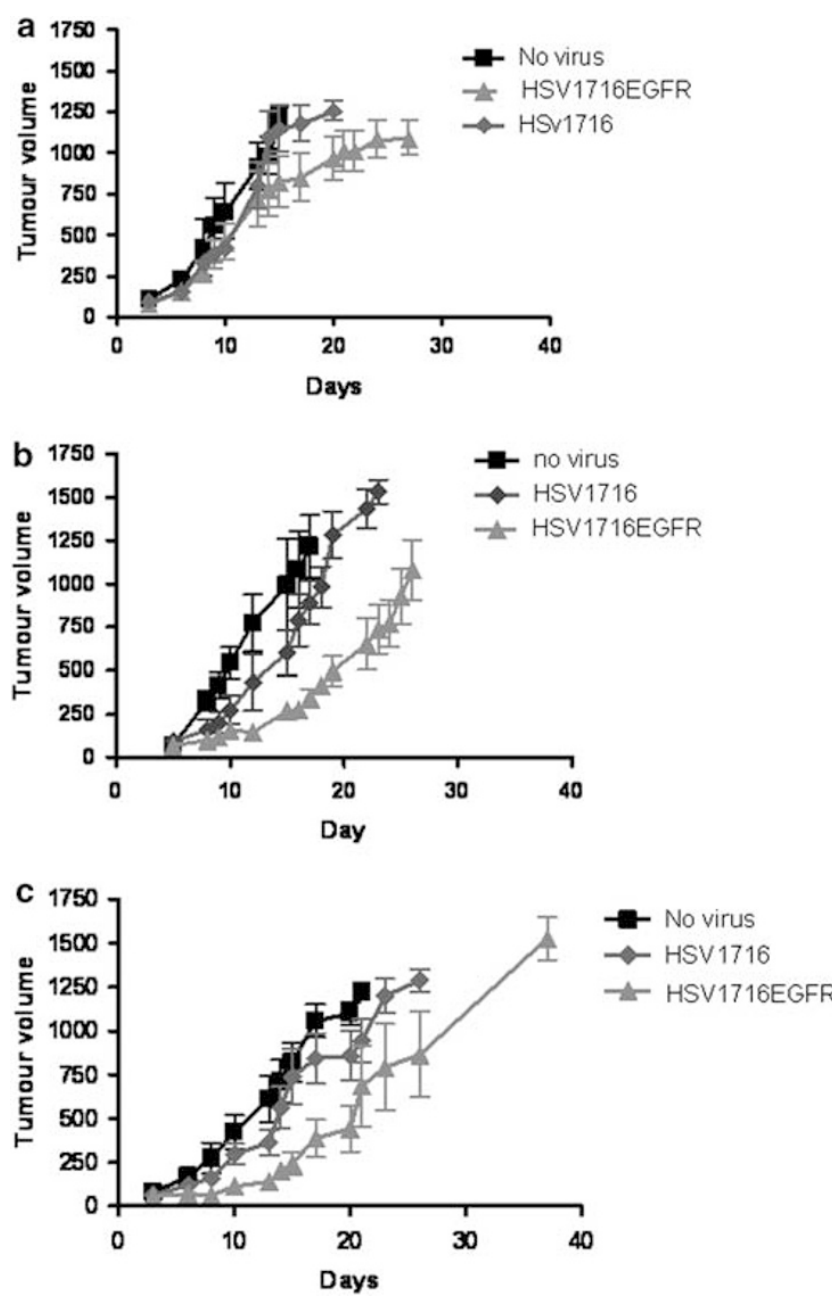

Figure 5 Graphs showing average tumour volumes in an A431 mouse tumour model after intravenous $(\mathbf{a}, \mathbf{b})$ or intraperitoneal $(\mathbf{c})$ injections of PBS (no virus control), HSV1716 or HSV1716EGFR. antibodies and replacing the heparan sulphate-binding region of $\mathrm{gC}$ with a 6-His tag improved virus binding to permissive 293 cells expressing a pseudo-His-tag receptor. ${ }^{33,35}$

Initially, we analysed the suitability of various glycoprotein $\mathrm{D}$ fragments to direct the incorporation of $\mathrm{N}$ terminally fused $\mathrm{scFv}$ into the HSV-1 envelope and, assessed the abilities of incorporated fusion proteins to alter the tropism of the virus. Although scFv/glycoprotein fusion proteins have been used to redirect the tropism of various different viruses including HSV-1, these studies have used the scFv linked to almost fulllength glycoproteins through the $\mathrm{N}$ terminus and optimization of incorporation and targeting ability have not been analysed. ${ }^{37}$ We linked a scFv from the wellcharacterized anti-GD3 ganglioside mAb, R24 to 15 sequentially deleted $\mathrm{gD}$ fragments and all of the constructs were created in mammalian-cell-expression vectors for stable cell line production. The resultant R24/ $\mathrm{gD}$ fusion proteins were incorporated into virus by infecting the cell lines with HSV1716-expressing green fluorescent protein, and epitope tagging of the fusion proteins allowed estimations of their levels of expression and incorporation into virus. The infectivity of the viruses derived from stable cell lines was assessed using fluorescence microscopy to monitor gfp expression in $\mathrm{CHO}$ cells that stained positively with $\mathrm{R} 24$, and results identified that the R24scFv linked to residues 274-393 of $\mathrm{gD}$ was very efficient at altering HSV1716 tropism. As $\mathrm{CHO}$ cells are non-permissive for Vero cell propagated HSV1716 infection, they provided an excellent system to assess alterations to viral tropism. ${ }^{45}$

Our initial analysis using infection of Vero cell lines to achieve viral assimilation of targeting moieties identified an efficient scFv mediated route to influence HSV1716 tropism. However, although this cell-based system was a convenient method to analyse a large number of different fusion protein constructs, production of targeted viruses is restricted to propagation on the appropriate cell line. Recombinant viruses expressing the targeting moieties during infection will be required and we produced a series of recombinant HSV1716 viruses expressing antiCD20, anti-CD38, anti-DAF or anti-EGFR scFv linked to $\mathrm{gD}$ residue 274 . These viruses were created using an efficient and rapid site-specific recombination protocol based on the Gateway cloning system. PCR confirmed the genomic structure at the RL1 loci of the HSV1716CD20, HSV1716CD38, HSV1716DAF and

Table 2 Comparisons of average tumour volumes from nude mice with subcutaneous A431 tumours injected intraperitoneally with either HSV1716EGFR or HSV1716

\begin{tabular}{|c|c|c|c|c|}
\hline Day & $\begin{array}{l}\text { HSV1716EGFR average } \\
\text { tumour volume } \pm \text { s.d. }\end{array}$ & $\begin{array}{l}\text { HSV1716 average } \\
\text { tumour volume } \pm \text { s.d. }\end{array}$ & P-value & Significant? \\
\hline 8 & $71.4 \pm 35.4$ & $120.1 \pm 24.3$ & 0.259 & No \\
\hline 10 & $62.9 \pm 22.8$ & $160.0 \pm 32.4$ & 0.051 & No \\
\hline 13 & $113.2 \pm 18.8$ & $296.9 \pm 57.6$ & 0.030 & Yes \\
\hline 14 & $140.6 \pm 27.6$ & $363.2 \pm 70.1$ & 0.032 & Yes \\
\hline 15 & $203.6 \pm 46.8$ & $563.0 \pm 117.2$ & 0.038 & Yes \\
\hline 17 & $244.4 \pm 60.7$ & $736.8 \pm 156.2$ & 0.033 & Yes \\
\hline 20 & $387.7 \pm 107.3$ & $843.0 \pm 142.1$ & 0.040 & Yes \\
\hline
\end{tabular}

Statistical analysis (ANOVA) was not possible after day 20 as most of the HSV1716-injected mice had died. 
HSV1716EGFR, and immunofluorescence/western blotting confirmed both expression of the $45 \mathrm{kDa}$ fusion proteins and their incorporation into virus. The orientation of the $\mathrm{scFv} / 274 \mathrm{gD}$-expression cassette relative to the PGK-gfp-expression cassette was important as one virus, in which the expression cassette for the anti-CD20scFv linked to residue 274 of $\mathrm{gD}$ was in reverse orientation, resulting in the close juxtaposition of the CMV-IE and PGK promoters, failed to express the $\mathrm{scFv} / \mathrm{gD}$ fusion protein. Elements of the PGK promoter immediately adjacent to the CMV-IE promoter must inhibit its transcriptional ability.

HSV1716DAF demonstrated redirected tropism of the virus with infection of the non-permissive, DAF-positive $\mathrm{CHO}$ cells mediated specifically through an interaction with cell-surface DAF. The infection of CHO/DAF cells was mediated specifically by the anti-DAFscFv linked to residue 274 of $\mathrm{gD}$ as $\mathrm{mAbDAF}$ or a recombinant mAbDAF minibody blocked infection by HSV1716DAF whereas the unrelated mAbCD20 or mAbCD38 had no effect. HSV1716CD38 showed enhanced infectivity for the semi-permissive CD38-positive SupT, THP-1 and TolB cells as, although HSV1716 can infect up to $30 \%$ of THP-1, SupT or TolB cells, suggesting the limiting presence of an HSV-1 receptor, most likely HVEM, the presence of a CD38-binding moiety displayed on the virus coupled with the cognate antigen on the cellular membrane, must have increased the proportion of specific virus/cellular interactions resulting in at least a doubling of infection rates. Significantly, these increased infection levels of SupT, THP-1 and TolB cells by HSV1716CD38 were specifically inhibited by mAbCD38 but not by mAbCD20.

Although an HSV1716 variant expressing an antiCD20scFv linked to $274 \mathrm{gD}$ was produced, no data demonstrating its abilities to alter tropism was generated. Unfortunately, the HSV1716CD20 did not enhance infection of the CD20-positive TolB cells although, as mAbCD20 only reacted weakly with TolB cells, possibly there was insufficient CD20 available on the cells to mediate viral penetration or, alternatively, as the minibody version of mAbCD20 failed to bind TolB cells (data not shown), perhaps mAbCD20 was unsuitable for conversion to the $\mathrm{scFv}$ format.

Using the EGFR-positive human squamous cell carcinoma cell line A431 to form subcutaneous tumours in nude mice, we were able to demonstrate that intravenously delivered HSV1716 targeted to EGFR by an anti-EGFR scFv linked to $274 \mathrm{gD}$ was better able to destroy tumours and promote survival than unmodified HSV1716. Indeed, the targeted viruses performed better than our initial data suggested as a number of mice that received HSV1716EGFR were killed prematurely because, although their apparent tumour diameters were $15 \mathrm{~mm}$, when the tumours were excised after killing, the bulk of the mass consisted of cellular detritus surrounding a much reduced tumour. Presumably, the EGFRbinding capability of the targeted HSV1716 variants augmented greatly the number of viruses locating to the tumour compared to the untargeted HSV1716 and this initial higher dose of virus adsorbed from the circulation was responsible for enhanced tumour destruction. Immunohistochemical and virus titration analysis of excised tumours confirmed that levels of virus replication in mice injected intravenously with HSV1716EGFR were much higher than in mice receiving unmodified HSV1716. Further evidence of the efficacy of tumour targeting was provided using intraperitoneal injection. By this route of administration, HSV1716 had no discernable effect on tumour growth whereas HSV1716EGFR significantly reduced tumour growth and prolonged survival.

These studies were performed to identify a reliable method for redesigning the tropism of oncolytic HSV such that systemically delivery will effectively target tumour cells. We have developed a plasmid-based system to link a mAb-derived scFv to gD residue 274 and recombinant viruses that display the targeting scFvs are produced rapidly using a novel in vitro site-specific recombination system. ScFvs have been used previously to target HSV-1 with an anti-EGFR scFv linked to the gDbinding domain of nectin-1 creating a soluble bridging molecule capable of attaching the virus to $\mathrm{CHO}$ cells displaying EGFR on their surface and insertion of an anti-HER2/neu $\mathrm{scFv}$ at $\mathrm{gD}$ residue 24 targeted the virus to $\mathrm{CHO}$ cells expressing the HER2/neu receptor. ${ }^{36,37}$ The soluble bridging molecule required $\mathrm{gD}$ to link virus and cell but the virus expressing the anti-HER2/neu scFv/gD fusion protein was $\mathrm{gD}$ negative. However, insertion of the $\mathrm{scFV}$ at residue 24 will only ablate HVEM binding and the chimaeric protein was still able to use nectin-1 as a receptor. Here, HSV1716 variants that express an antiDAF scFv or an anti-CD38 scFv linked to gD residue 274 mediated infection by cognate antigen binding, although the recombinant viruses retained $\mathrm{gD}$, and apparently, their abilities to infect cells using either HVEM or nectin1 was unaffected. Possibly, the fusion proteins can function as the sole receptor-binding protein to mediate infection of targeted cells as the $\mathrm{scFv}$ will mimic the specific interaction required to tether the virus closely to the cellular membrane and membrane fusion will be elicited by the remaining membrane-proximal residues of $\mathrm{gD}$ that form a profusion domain required for recruitment of $\mathrm{gB}$ and $\mathrm{gH} / \mathrm{gL} .{ }^{46}$ Currently, we are attempting to create a gD-negative HSV1716 variant but, as $\mathrm{gD}$ is an essential protein, such a virus will be severely attenuated or even replication incompetent and it is interesting to speculate whether a gD-negative virus is mandatory to achieve optimal tumour targeting. Certainly, HSV1716 variants displaying both the targeting moiety and native gD will still be able to infect offtarget cells expressing HSV-1 receptors but, as demonstrated by HSV1716EGFR, the targeting moiety enhanced tumour uptake and destruction compared to unmodified HSV1716 suggesting that adsorption by non-tumour cells of systemically injected HSV1716 variants is not a major issue. Neutralizing antibodies that target gD may also be a problem for such systemically administered HSV1716 variants and ablation of the gD ORF will prevent this. However, once a tumour has been infected with a targeted, gD-negative HSV1716 variant, spread to other tumour cells within the mass will be totally dependent on the specific $\mathrm{scFv} /$ antigen interaction. As heterogeneity is a feature of many tumour types, not all cells will display the specific membrane protein and will therefore avoid infection. Thus, the presence of both the $\mathrm{scFv} / \mathrm{gD}$ fusion protein and $\mathrm{gD}$ in the virus envelope is possibly a more effective configuration allowing an initial high level of tumour uptake followed by optimum infection rates. 


\section{Materials and methods}

Cells and viruses

BHK, CHO-K1 and Vero cells were grown as previously described..$^{45}$ Hybridomas mAbR24, mAbIF5 (mAbCD20), mAbTHB-7 (mAbCD38) and mAb108 (mAbEGFR), expressing $\mathrm{mAbs}$ against the ganglioside GD3, CD20, CD38 or EGFR, respectively, and the human leukaemic SupT, THP-1 and TolB cell lines, were obtained from ATCC/ LGCpromochem (London, UK) and were cultured in RPMI1640 medium supplemented with 10\% NCS. Hybridoma HD1B (mAbDAF) that expresses a mAb that recognizes human DAF/CD55, a kind gift from Dr Claire Harris, Department of Medical Biochemistry, University of Wales College of Medicine, Cardiff, UK, was also maintained in RPMI1640 medium supplemented with $10 \%$ NCS. HSV1716gfp is described in Harland et al. ${ }^{6}$ and production of virus stocks is described in Conner et al. ${ }^{45}$

\section{Preparation of scFvs from hybridoma cells}

Hybridoma cells were grown to high density and cell pellets obtained by centrifugation at $1000 \mathrm{~g}$ for $5 \mathrm{~min}$. Total RNA was extracted using the SV Total RNA kit (Promega, Southampton, UK) and cDNA prepared using the ImProm II Reverse Transcription System (Promega). Recombinant $\mathrm{scFv}$ variants of the $\mathrm{mAbs}$ were derived from these cDNAs using the protocols and PCR primers described by Pope et al. ${ }^{47}$ Briefly, scFv-encoding DNAs for each $\mathrm{mAb}$ were prepared by RT-PCR amplification and linkage of antibody VH and VL sequences with the scFv-encoding DNAs then amplified using PCR primers that incorporate SfiI and NotI restriction enzymes sites at the $5^{\prime}$ and $3^{\prime}$ ends, respectively, for cloning in the phagemid vector pCANTAB6. Competent Escherichia coli cells (strain HB2151) were transformed with the phagemid vectors and $\mathrm{scFv}$ expression by IPTG induction was confirmed by western blotting (data not shown); scFvs expressed from pCANTAB6 have myc tags for detection.

\section{Construction of $p E L 4$, a vector for scFv/glycoprotein fusion protein production}

Plasmid pEL4 for expression of scFv/glycoprotein fusion proteins was created to allow PCR-amplified scFv DNAs to be cloned in-frame downstream of an immunoglobulin G (IgG) heavy chain leader sequence as SfiI/NotI fragments and in-frame upstream of a PCR-amplified HSV-1 glycoprotein DNA fragment. Initially, using pCANTAB6 with an R24 scFv insert as template, the scFv DNA was amplified using primers ELsfifor and R24notrev.

Primer ELsfifor is a 99-base oligonucleotide (GAATT CATGGGATGGAGCTGTATCATCCTCTTCTTGGTAGC AACAGCTACAGGTGTCCACTCCGCGGCCCAGCCG GCCGATGTGCAACTGGTGGAGTCT) that has a $5^{\prime}$ $\overline{E c o R} 1$ site (in bold) then 63 bases (underlined) encode the R24 IgG heavy chain leader sequence followed by the R24 scFv 5' sequence with an intervening SfiI site (in bold and underlined). PCR with ELsfifor and R24notrev (GAGTCATTCTGCGGCCGCCCGTTTTATCTCCAGCT TGGT), the anti-sense primer exactly matching the $3^{\prime}$ end of the R24 scFv with a NotI site (in bold), generated the R24 scFv DNA for cloning into the EcoR1/Not1 sites in the mammalian-expression plasmid pCDNA4myc/HisA (Invitrogen, Paisley, UK) to generate pEL4.

The presence of the IgG leader in this plasmid was confirmed by sequencing. The R24 scFv component in pEL4 can be readily exchanged with an alternative $\mathrm{scFv}$, amplified by PCR using primers that provide flanking SfiI/NotI sites. ${ }^{47}$ As each of the scFvs created in this study has a unique $\mathrm{RsaI}$ fingerprint, any $\mathrm{scFv}$ exchange was confirmed by PCR amplification of the scFv DNA and RsaI digestion (data not shown).

\section{Construction of vectors for the expression of scFv/glycoprotein fusion proteins}

For HSV-1 gD, which comprises 393 aa with the TM domain located between aa 342 and 364, 15 random deletions sequentially removing aa $1-273$ were PCR amplified using the 15 forward and common reverse primers shown in Table 3. The gD forward primers are identified by the extent of the N-terminal deletion (for example, primer $108 \mathrm{gD}$ amplified a gD DNA fragment with 36 codons deleted from the $\mathrm{N}$ terminus and starts at nucleotide 109/codon 37). An additional A nucleotide between the Not 1 site (in bold) and the gD sequences (underlined) ensured that the $\mathrm{gD}$ and $\mathrm{scFv}$ DNAs were cloned in frame; the Not 1 site plus the additional A inserts an Ala-Ala-Ala linker between the $\mathrm{scFv}$ and glycoprotein domains of the fusion protein. The $\mathrm{gD}$ reverse primer lacks a stop codon and the XhoI site used for cloning ensured that the inserted fragment was in frame with the Myc/His tags provided by the pCDNA4 parent vector. After PCR amplification from viral DNA, the $\mathrm{gD}$ fragment was sequentially digested with NotI, followed by XhoI and ligated into the likewise digested pEL4 containing the scFv DNAs. The gD PCR fragments were also cloned into pGEMT-easy and sequenced to confirm their identity (data not shown).

\section{Production of stable cell lines expressing scFv/glycoprotein fusion proteins}

Vero cells were transfected with $50 \mu \mathrm{g} \mathrm{scFv} / \mathrm{gD}$ fusion protein-encoding plasmids mixed with $10 \mu \mathrm{l}$ lipofectamine 2000 (Invitrogen) in $250 \mu \mathrm{l}$ of serum-free Dulbecco's modified Eagle's medium (DMEM)/F12 medium. After

Table 3 Sequences of primers used for the PCR amplification of sequentially deleted gD fragments. Restriction sites are in bold and HSV-1 glycoprotein sequences are underlined

$g D$ forward primers

108gD GGATCCGCGGCCGCAGCCGACCCCAATCGCTTTCGCGGC

171gD GGATCCGCGGCCGCAGGGGTCCGGCGCGTGTACCACATC

231gD GGATCCGCGGCCGCACTCCCGATCACGGTTTACTACGCC

273gD GGATCCGCGGCCGCA $\overline{C G C A G C G T G C T C C T A A A C G C A C C G}$

312gD GGATCCGCGGCCGCAATTGT CCGCGGGGCC TCCGAAGAC

381gD GGATCCGCGGCCGCAGGAGGCAACTGTGCTATCCCCATC

414gD GGATCCGCGGCCGCA GAGTA CACCGAATGC TCCTACAAC

489gD GGATCCGCGGCCGCA GACAGCTTCAGCGCCGTCAGCGAG

534gD GGATCCGCGGCCGCACACGCCCCCGCGTTTGAGACCGCC

570gD GGATCCGCGGCCGCACGGCTCGTGAAGATAAACGACTGG

618gD GGATCCGCGGCCGCA GAGCACCGAGCCAAGGGCTCCTGT

690gD GGATCCGCGGCCGCACAGGCCTACCAGCAGGGGGTGACG

714gD GGATCCGCGGCCGCA GTGGACAGCATCGGGATGCTGCCC

777gD GGATCCGCGGCCGCAAGCTTGAAGATCGCCGGGTGGCAC

819gD GGATCCGCGGCCGCAACGAG CACCCTGCTG CCCCCGGAG

$g D$ reverse primer

GGCCAAGCTTCTCGAGTCTAGAGTAAAACAAGGGCTGGTGCGAGGA 
48-72 h of transfection, cells were trypsinized and plated out with growth medium containing $1 \mathrm{mg} \mathrm{ml}^{-1}$ zeocin (Invitrogen). Cells were selected with the zeocin antibiotic for 2-3 weeks after which time individual clones were clearly visible. Cells were trypsinized and cloned by limiting dilutions in 24-well plates. Clones were expanded and maintained in appropriate medium containing $1 \mathrm{mg} \mathrm{ml}^{-1}$ zeocin. Expression of scFv/glycoprotein fusion proteins was confirmed either by western blotting or by immunofluorescence using an anti-myc $\mathrm{mAb}$ (New England Biolabs, Hitchin, UK).

For production of virus stocks, confluent monolayers of stable cell lines were infected with $1 \times 10^{5}$ PFU HSV1716gfp and, after 3-4 days of infection, total virus was harvested, purified by high-speed centrifugation and titrated on BHK cells. All yields were within the range obtained for HSV1716gfp infection of normal Vero cells (data not shown). The presence of scFv/glycoprotein fusion proteins in the virion was confirmed by western blotting using the anti-myc mAb.

\section{Production of viruses expressing scFv/gD fusion proteins by site-specific recombination}

A series of targeted viruses was constructed with scFvs linked to residue 274 of $\mathrm{gD}$ using a novel in vitro sitespecific recombination system. Central to this method was production of HSV1716GateRed, an HSV1716 variant, which contained Gateway destination sites located within each of the ICP34.5 deleted regions. The Gateway Vector Conversion system (Invitrogen) provided DNA with attR site-specific recombination sequences for insertion into a vector of choice and was blunt-end ligated into plasmid sp73 to create sp73gate. Once inserted in the plasmid, the DNA between the attR sites, encoding chloramphenicol resistance and the $c c d B$ gene, was removed by Not1/BstXI digestion. The bluntended vector backbone was then ligated with a bluntended $1.3 \mathrm{kbp}$ CMV-DSred-expression cassette, excised from the plasmid pCMV-DsRed-Express (BD Biosciences, Cowley, UK) by AflII/NsiI digestion, to create the plasmid sp73gatered. The DNA consisting of the attR sites flanking the CMV-DSred-expression cassette was excised from sp73gatered by $B g l \mathrm{II} / \mathrm{XhoI}$ digestion, blunt ended with Klenow and ligated into the blunt-ended, alkaline phosphatase-treated BglII site in the plasmid RL1-del used for the production of HSV1716 variants by homologous recombination. RL1-del consists of the HSV1 BamHI k-DNA fragment (123459-129403) that includes the RL1 gene and its flanking sequences cloned into the BamHI site of plasmid pGem-3Zf (Promega). The $477 \mathrm{bp}$ PflMI/BstEII fragment from the RL1 ORF (125292-125769) has been removed to inactivate the ICP34.5 gene and replaced with a multi-cloning site (MCS) providing unique $B g l \mathrm{II}, \mathrm{NruI}$ and $\mathrm{XhoI}$ restriction enzymes sites. The transgene to be inserted into the RL1 loci is ligated into the MCS of RL1-del and homologous recombination with HSV-1 DNA, driven by the RL1 flanking sequences, results in concomitant deletion of the ICP34.5 gene and incorporation of the desired transgene. Southern blotting confirmed that the Gateway destination sites flanking the DsRed-expression cassette was cloned into both RL1 loci (data not shown).

The Gateway entry vector, $p E N T R 1 A$ was modified for use in our HSV1716 site-specific recombination system as follows. The DNA between the attL sites in pENTR1A was removed by EcoR1 digestion and the resulting blunt-ended vector backbone was ligated with a green fluorescent protein-expression cassette comprising the $1.3 \mathrm{kbp}$ blunt-ended EcoRI/AflII fragment that contains the PGK promoter/gfp gene excised from the vector pSNRG (a kind gift from Dr B Singh (MSKCC, New York, USA)). Although EcoR1 digestion removed the $c c d B$ gene from pENTR1A, a number of other restriction sites between the attL flanking sequences were retained for insertion of additional gene/DNA sequences of interest to be cloned into HSV1716 alongside the PGK-gfpexpression cassette.

Novel HSV1716 variants were created in vitro by incubating HSV1716GateRed DNA with the appropriate gene/DNA sequence of interest inserted in pENTR1Agfp. HSV1716GateRed DNA was obtained by phenol/ chloroform extraction of BHK cells $24 \mathrm{~h}$ after infection with the HSV1716GateRed virus and, after 70\% isopropanol precipitation, the DNA was resuspended in $1 \mathrm{ml}$ nuclease-free water. The expression cassettes for the $\mathrm{scFv} / 274 \mathrm{gD}$ fusion proteins were excised directly from the appropriate pEL4 constructs as $2.3 \mathrm{kbp}$ SspI/PvuII fragments that contained the CMV-IE promoter, the $\mathrm{scFv} / \mathrm{gD}$ encoding DNA and the $\mathrm{BGH}$ polyadenylation signal. These fragments were ligated directly into the plasmid pENT1A-gfp, which had been BamHI digested, blunt ended with Klenow and alkaline phosphatase treated. For site-specific recombination reactions using these pENTR1A-gfp constructs, $5 \mu \mathrm{g}$ plasmids and $3 \mu \mathrm{g}$ HSV1716GateRed DNA were incubated overnight with LR clonase. After enzyme inactivation by Proteinase $\mathrm{K}$ digestion, the entire reaction $\operatorname{mix}(11 \mu \mathrm{l})$ was added to $250 \mu \mathrm{l}$ of serum-free DMEM/F12 (Invitrogen) medium containing $10 \mu \mathrm{l}$ lipofectamine 2000 and used to transfect $50 \%$ confluent BHK cells in a $60 \mathrm{~mm}$ dish. After $4-6 \mathrm{~h}$, the cells were shocked in $25 \%$ dimethyl sulfoxide/PBS, washed and cultured in $5 \mathrm{ml}$ of Glasgow minimum essential medium at $37^{\circ} \mathrm{C}$ for $48-72 \mathrm{~h}$. Cells were harvested by scraping into the medium and, after $2 \mathrm{~min}$ sonication, 5 sequential 10 -fold dilutions were plated out on Vero cells. The in vitro site-specific recombination reaction was very efficient and converted up to $90 \%$ of viral DNA from DsRed to gfp expression such that, a single plaque picked from the serially diluted plates was $100 \%$ pure with no DsRed virus contamination and was used for HSV1716 recombinant stock production. PCR, with primers that amplify across the ICP34.5 deleted region was used to confirm the appropriate genomic structure at the RL1 loci of these viruses with viral DNA prepared using a Wizard SV genomic DNA kit from BHK cells $24 \mathrm{~h}$ after infection with the relevant viruses at $5 \mathrm{PFU}$ per cell (data not shown).

\section{Production of $\mathrm{CHO}$ cell lines expressing human $\mathrm{CD} 55$} and a recombinant $m A b B$ minibody

Plasmid pDAF, which contains a mammalian-expression cassette for human CD55 with a hygromycin selectable marker, was a kind gift from Dr Claire Harris and was used to transfect $\mathrm{CHO}$ cells. Plasmid $(50 \mu \mathrm{g})$, mixed with $0.25 \mathrm{ml}$ serum-free DMEM/F12 medium containing $10 \mu \mathrm{l}$ lipofectamine 2000, was added to $\mathrm{CHO}$ cells and, after $48 \mathrm{~h}$ in culture, cells were trypsinized and plated out in a 
T75 flask in growth medium supplemented with $0.5 \mathrm{mg} \mathrm{ml}^{-1}$ hygromycin. After 14 days in culture individual colonies of cells were trypsinized and, after cloning by limiting dilution, a stable hygromycinresistant $\mathrm{CHO}$ cell line, termed $\mathrm{CHO} / \mathrm{DAF}$, which expressed CD55, as assessed by western blotting using mAbDAF, was produced. The $\mathrm{CHO} / \mathrm{DAF}$ cell line was maintained in DMEM/F12 supplemented with $10 \%$ NCS and $0.5 \mathrm{mg} \mathrm{ml}^{-1}$ hygromycin.

Using the anti-DAF scFv DNA cloned into pEL4, an expression cassette for a minibody construct comprising the scFv DNA linked to the human IgG1 CH2/CH3 (Fc) region DNA was prepared. The resultant expressed protein was able to dimerize by the IgG1 Fc region and was secreted into the medium from a stable CHO cell line isolated using the zeocin resistance gene of pEL4. The $5^{\prime}$ and $3^{\prime}$ primers for the amplification of the human IgG1 Fc DNA, which incorporate Not1 and Xho1 restriction sites (underlined), were respectively ACC TTGCAGCGGCCGCAAGACCCAAATCTTGTGACAAA ACTC and GATCACGTCTCGAGTTATCATTTACC CGGAGACAGGGAGAGGCTCTTTCTG and these were used to amplify the $700 \mathrm{bp}$ IgG1 Fc region from peripheral blood mononuclear cell total RNA by RT-PCR. The amplified fragment was cloned directly after RT-PCR into the PCR cloning vector pGEM-Teasy (Promega) and was sequenced to confirm its identity. The PCR fragment was digested sequentially using Not1 followed by Xho1 and ligated into the pEL4 plasmid containing the anti-DAFscFv to generate a plasmid that expresses the DAFscFv linked to the human IgG1 Fc region. $\mathrm{CHO}$ cells were transfected and selected as described above except that the growth medium contained $1 \mathrm{mg} \mathrm{ml}^{-1}$ zeocin for selection rather than hygromycin. Medium from zeocin-resistant stable cell lines was harvested after 5 days in culture and expression of the mAbDAF minibody was confirmed by denaturing and non-denaturing PAGE/western blotting using an anti-human IgG Fc antibody which identified respective 55 and $110 \mathrm{kDa}$ proteins (data not shown).

\section{Fluorescence microscopy/western blotting/ immunofluorescence}

As HSV1716 variants used in this study expressed gfp, the infectivity of progeny viruses was assessed by fluorescence microscopy as described in Conner et al. ${ }^{45}$ For western blotting, cell lines to be infected with the various HSV1716 variants expressing $\mathrm{scFv} / 274 \mathrm{gD}$ fusion proteins were plated out in $35 \mathrm{~mm}$ plates and incubated for $24 \mathrm{~h}$ at $37{ }^{\circ} \mathrm{C}$ in $5 \% \mathrm{CO}_{2}$ before infection. For harvesting, cells were washed once with $1 \mathrm{ml}$ PBS and whole-cell extracts obtained by the direct addition of $0.2 \mathrm{ml}$ SDS-PAGE sample buffer. After SDS-PAGE and transfer to nitrocellulose membranes, blots were probed with the anti-myc mAb diluted 1:1000. To determine the presence of $\mathrm{scFv} /$ glycoprotein fusion proteins in virions, $1 \times 10^{6}$ PFU purified virus were mixed with $0.1 \mathrm{ml}$ SDSPAGE sample buffer and analysed as described above. To assess infectivity of targeted viruses, confluent monolayers of cells were infected with virus and incubated for 8-24 h before cells were harvested as described above. Blots were probed with a polyclonal antibody to the R1 subunit of the viral ribonucleotide reductase. ${ }^{48}$ For immunofluorescence to detect $\mathrm{scFv} / 274 \mathrm{gD}$ fusion protein expression by HSV1716 variants, BHK cells were plated out on glass coverslips, cells were infected with the appropriate virus at $1 \mathrm{PFU}$ per cell for $24 \mathrm{~h}$ and cells were fixed in $4 \%$ paraformaldehyde. After blocking for $1 \mathrm{~h}$ in $2 \%$ normal horse serum, cells were incubated overnight in the anti-myc mAb diluted 1:1000, washed four times in PBS with $0.05 \%$ Tween (PBST) and incubated for $2-4 \mathrm{~h}$ either in anti-mouse $\mathrm{IgG} /$ fluorescein isothiocyanate (FITC) or IgG/Texas Red conjugate (Vector Laboratories Ltd, Peterborough, UK) diluted 1:200. For immunofluorescence with the recombinant mAbDAF minibody, an anti-human Fc/FITC conjugate at 1:1000 was used. After four washes in PBST, coverslips were mounted and analysed by fluorescence microscopy.

\section{In vivo tumour reduction studies}

Female 6- to 8-week-old athymic nude mice (Charles River Laboratories, UK) were maintained under specific pathogen-free conditions. Actively growing A431 cells were harvested and, after resuspension in PBS, $1 \times 10^{6}$ cells per mouse were injected subcutaneously. When tumours reached $5 \mathrm{~mm}$ in diameter, the mice were injected either intravenously via the tail vein or intraperitoneally with PBS, HSV1716 or HSV1716EGFR. Mice were inspected daily, when tumour diameters reached $15 \mathrm{~mm}$ they were killed and the tumour xenograft removed for immunohistochemistry/viral extraction. The viral load in tumours and various organs was assessed by plaque-forming assay on BHK cells. Extracted intact tumours/organs were frozen immediately at $-70{ }^{\circ} \mathrm{C}$ and, after thawing, the tissues were mechanically homogenized in a Retsch homogenizer in $1 \mathrm{ml}$ PBS prior to titration.

For immunohistochemistry, tumour samples were fixed for at least $24 \mathrm{~h}$ in $4 \%$ paraformaldehyde before embedding and sectioning using standard protocols. Briefly, paraffin-embedded sections were dewaxed, dehydrated and endogenous peroxidase activity quenched. Sections were blocked with $10 \%$ normal goat serum before incubation in an anti-HSV-1 polyclonal primary antibody (DakoCytomation, Ely, UK) diluted 1:1000. A biotinylated secondary antibody at 1:500 dilution, an avidin/biotin complex solution and the chromagen DAB (all from Vector Laboratories Ltd) were then used to detect the primary antibody binding to tissue. The slides were counterstained, dehydrated mounted and analysed using light microscopy.

\section{Acknowledgements}

This work was supported in part by the SPUR PLUS programme from the Scottish Executive.

\section{References}

1 Aghi M, Martuza RL. Oncolytic viral therapies-the clinical experience. Oncogene 2005; 24: 7802-7816.

2 Chiocca EA. Oncolytic viruses. Nat Rev Cancer 2002; 2: 938-950.

3 MacLean AR, Fareed MU, Robertson L, Harland J, Brown SM. Herpes simplex virus type 1 deletion variants 1714 and 1716 pinpoint neurovirulence related sequences in Glasgow strain $17+$ between immediate early gene 1 and the ' $a$ ' sequence. J Gen Virol 1991; 72: 631-639. 
4 Brown SM, Harland J, MacLean AR, Podlech J, Clements JB. Cell type and cell state determine differentiated in vitro growth of non-neuroviulent ICP34.5-negative herpes simplex virus. J Gen Virol 1994; 75: 2367-2377.

5 Brown SM, MacLean AR, McKie EA, Harland J. The herpes simplex virus virulence factor ICP34.5 and the cellular protein MyD116 complex with proliferating cell nuclear antigen through the 63-amino acid domain conserved in ICP34.5, MyD116 and GADD34. J Virol 1997; 71: 9442-9449.

6 Harland J, Dunn P, Cameron E, Conner J, Brown SM. The herpes simplex virus (HSV) protein ICP34.5 is a virion component that forms a DNA-binding complex with proliferating cell nuclear antigen and HSV replication proteins. J Neurovirol 2003; 9: 477-488

7 Rampling R, Cruikshank G, Papanastassiou V, Nicoll J, Hadley $\mathrm{D}$, Brennan $\mathrm{D}$ et al. Toxicity evaluation of replication-competent herpes simplex virus (ICP 34.5 null mutant 1716) in patients with recurrent malignant glioma. Gene Therapy 2000; 7: 859-866.

8 Papanastassiou V, Rampling R, Fraser M, Petty R, Hadley D, Nicoll $\mathrm{J}$ et al. The potential for efficacy of the modified (ICP 34.5(-)) herpes simplex virus HSV1716 following intratumoural injection into human malignant glioma: a proof of principle study. Gene Therapy 2002; 9: 398-406.

9 Harrow S, Papanastassiou V, Harland J, Mabbs R, Petty R, Fraser $\mathrm{M}$ et al. HSV1716 injection into the brain adjacent to tumour following surgical resection of high-grade glioma: safety data and long term survival. Gene Therapy 2004; 11: 1648-1658.

10 MacKie RM, Stewart B, Brown SM. Intralesional injection of herpes simplex virus 1716 in metastatic melanoma. The Lancet 2001; 357: 525-526.

11 Mace AT, Ganly I, Soutar S, Brown SM. Potential for efficacy of the oncolytic herpes simplex virus 1716 in patients with oral squamous cell carcinoma. Head Neck 2008; 30: 1045-1051.

12 McCormick F. Future prospects for oncolytic therapy. Oncogene 2005; 24: 7817-7819.

13 Wickham TJ. Ligand-directed targeting of genes to the site of disease. Nat Med 2003; 9: 135-139.

14 Galmiche MC, Rindisbacher L, Wels W, Wittek R, Buchegger F. Expression of a functional single chain antibody on the surface of extracellular enveloped vaccinia virus as a step towards selective tumour cell targeting. J Gen Virol 1997; 78: 3019-3027.

15 Chowdhury S, Chester KA, Bridgewater J, Collons MK, Martin F. Efficient retroviral vector targeting of cancinoembryonic antigen-positive tumours. Mol Ther 2004; 9: 85-92.

16 Khare PD, Shao-Xi L, Kuroki M, Hirose Y, Arakawa F, Nakamura $\mathrm{K}$ et al. Specifically targeted killing of cancinoembryonic antigen (CEA)-expressing cells by a retroviral vector displaying single chain variable fragmented antibody to CEA and carrying the gene for inducible nitric oxide synthase. Cancer Res 2001; 61: 370-375.

17 Nguyen TH, Loux N, Bagher I, Vons C, Carey K, Briand P et al. Improved gene transfer selectivity to hepatocarcinoma cell by retrovirus vector displaying single-chain variable fragment antibody against c-Met. Cancer Gene Ther 2003; 10: 840-849.

18 Marin M, Noel D, Valsesia-Mittman S, Brockly F, Etienne-Julan M, Russell $\mathrm{S}$ et al. Targeted infection of human cells via major histocompatibility complex class 1 molecules by Moloney murine leukemia virus-derived viruses displaying single-chain antibody fragment-envelope fusion proteins. J Virol 1996; 70: 2957-2962.

19 Aires Da Silva F, Costa MJL, Corte-Real S, Goncalves J. Cell typespecific targeting with Sindbis pseudotyped lentiviral vectors displaying anti-CCR5 single-chain antibodies. Hum Gene Ther 2005; 16: 223-234.

20 Martin F, Neil S, Kupsch J, Maurice M, Cosset F-L, Collins M. Retrovirus targeting by tropism restriction to melanoma cells. J Virol 1999; 73: 6923-6929.
21 Bucheit AD, Kumar S, Grote DM, Lin Y, von Messling V, Cattaneo RB et al. An oncolytic measles virus engineered to enter cells through the CD20 antigen. Mol Ther 2003; 7: 62-72.

22 Peng K-W, Donovan KA, Schneider U, Cattaneo R, Lust JA, Russell SJ. Oncolytic measles viruses displaying a single chain antibody against CD38, a myeloma cell marker. Blood 2003; 101: 2557-2562.

23 Watkins SJ, Mesyanzhinov VV, Kurochkina LP, Hawkins RE. The 'adenobody' approach to viral targeting: specific and enhanced adenoviral gene delivery. Gene Therapy 1997; 4: 1004-1012.

24 Haisma HJ, Grill J, Curiel DT, Hoogeland S, van Beusechem VW, Pinedo HM et al. Targeting of adenoviral vectors through a bispecific single chain antibody. Cancer Gene Ther 2000; 7: 901-904.

25 Nettelbeck DM, Miller DW, Jerome V, Zuzarte M, Watkins SJ, Hawkins RE et al. Targeting of adenovirus to endothelial cells by a bispecific single-chain diabody directed against the adenovirus fiber knob domain and human endoglin (CD105). Mol Ther 2001; 3: 882-891.

26 Pereboev AV, Asiedu CK, Kawakami Y, Dong SS, Blackwell JL, Kashentseva EA et al. Coxsackievirus-adenovirus receptor genetically fused to anti-human CD40 scFv enhances adenoviral transduction of dendritic cells. Gene Therapy 2002; 9: 1189-1193.

27 van Beusechem VW, Mastenbroek DCJ, van den Doel PB, Lamfers MLM, Grill J, Wurdinger $\mathrm{T}$ et al. Conditionally replicative adenovirus expressing a targeting adapter molecule exhibits enhanced oncolytic potency on CAR-deficient tumors. Gene Therapy 2003; 10: 1982-1991.

28 Nettelbeck DM, Rivera AA, Kupsch J, Dieckmann D, Douglas JT, Kontermann RE et al. Retargeting of adenovirus infection to melanoma: combining genetic ablation of native tropism with a recombinant bispecific single-chain diabody $(\mathrm{scDb})$ adapter that binds to fiber knob and HMWMAA. Int J Cancer 2004; 108: 136-145.

29 Breidenbach M, Rein DT, Everts M, Glasgow JN, Wang M, Passineau MJ et al. Mesothelin-mediated targeting of adenoviral vectors for ovarian cancer gene therapy. Gene Therapy 2005; 12: 187-193.

30 Laquerre S, Anderson DB, Stolz DB, Glorioso JC. Recombinant herpes simplex virus type 1 engineered for targeted binding to erythropoietin receptor-bearing cells. J Virol 1998; 72: 9683-9697.

31 Zhou G, Ye G-J, Debinski W, Roizman B. Engineered herpes simplex virus type 1 is dependent on IL13R $\alpha 2$ receptor for cell entry and independent of glycoprotein $\mathrm{D}$ receptor interaction. Proc Natl Acad Sci USA 2002; 99: 15124-15129.

32 Zhou G, Roizman B. Characterization of a recombinant herpes simplex virus type 1 designed to enter cells via the IL13R $\alpha 2$ receptor of malignant glioma cells. J Virol 2005; 79: 5272-5277.

33 Argnani R, Boccafogli L, Marconi PC, Manservigi R. Specific targeted binding of herpes simplex type 1 to hepatocytes via the human hepatitis B virus preS1 peptide. Gene Therapy 2004; 11: 1087-1098.

34 Kamiyama H, Zhou G, Roizman B. Herpes simplex virus 1 recombinant virions exhibiting the amino terminal fragment of urokinase-type plasminogen activator can enter cells via the cognate receptor. Gene Therapy 2005; 12: 1-9.

35 Grandi P, Wang S, Schuback D, Krasnykh V, Spear M, Curiel DT et al. HSV-1 virions engineered for specific binding to cell surface receptors. Mol Ther 2004; 9: 419-427.

36 Nakano K, Asano R, Tsumoto K, Kwon H, Goins WF, Kumagai I et al. Herpes simplex virus targeting to the EGF receptor by a gD-specific soluble bridging molecule. Mol Ther 2005; 11: 617-626.

37 Menotti L, Cerretani A, Campadelli-Fiume G. A herpes simplex virus recombinant that exhibits a single chain antibody to HER2/neu enters cells through the mammary tumor receptor, independently of the gD receptors. J Virol 2006; 80: 5531-5539.

38 Spear PG, Longnecker R. Herpesvirus entry: an update. J Virol 2003; 77: 10179-10185. 
39 Spear PG. Herpes simplex virus: receptors and ligands for cell entry. Cell Microbiol 2004; 6: 401-410.

40 Cocchi F, Menotti L, Mirandola P, Lopez M, Campadelli-Fiume G. The ectodomain of a novel member of the immunoglobulin subfamily related to the poliovirus receptor has the attributes of a bona fide receptor for herpes simplex virus types 1 and 2 in human cells. J Virol 1998; 72: 9992-10000.

41 Haarr L, Shukla D, Rodahl E, Dal Canto MC, Spear PG. Transcription from the gene encoding the herpesvirus entry receptor nectin 1 (HveC) in nervous tissue of adult mouse. Virology 2001; 287: 301-309.

42 Mata M, Zhang M, Hu X, Fink DJ. HveC (nectin-1) is expressed at high levels in sensory neurons, but not in motor neurons, of the rat peripheral nervous system. J Neurovirol 2001; 7: 476-480.

43 Richart SM, Simpson SA, Krummenacher C, Whitbeck JC, Pizer LI, Cohen GH et al. Entry of herpes simplex virus type 1 into primary sensory neurons in vitro is mediated by nectin-1/ HveC. J Virol 2003; 77: 3307-3311.
44 Montgomery RI, Warner MS, Lum BJ, Spear PG. Herpes simplex virus-1 entry into cells mediated by a novel member of the TNF/NGF receptor family. Cell 1996; 87: 427-436.

45 Conner J, Rixon FJ, Brown SM. Herpes simplex virus type 1 strain HSV1716 grown in baby hamster kidney cells has altered tropism for nonpermissive Chinese hamster ovary cells compared to HSV1716 grown in Vero cells. J Virol 2005; 79: 9970-9981.

46 Cocchi F, Fusco D, Menotti L, Gianni T, Eisenberg RJ, Cohen GH et al. The soluble ectodomain of herpes simplex virus $\mathrm{gD}$ contains a membrane-proximal pro-fusion domain and suffices to mediate virus entry. Proc Natl Acad Sci USA 2004; 101: 7445-7450.

47 Pope AR, Embleton MJ, Mernaugh R. Construction and use of antibody gene reportoires. In: McCafferty J, Hoogenboom HR, Chiswell DJ (eds). Antibody Engineering A Practical Approach. IRL Press: Oxford, pp 1-40.

48 Conner J, Furlong J, Murray J, Meighan M, Cross A, Marsden H et al. Herpes simplex virus type 1 ribonucleotide reductase large subunit: regions of the protein essential for subunit interaction and dimerization. Biochemistry 1993; 32: 13673-13680. 